\title{
Is there an association between vitamin D and liver fibrosis in patients with chronic hepatitis C?
}

\author{
Kalinca da Silva OLIVEIRA ${ }^{1}$, Caroline BUSS ${ }^{1,2}$ and Cristiane Valle TOVO0 ${ }^{1,3}$
}

ABSTRACT - Background - Vitamin D is known for its immunomodulatory, anti-inflammatory and antifibrotic properties, which are quite relevant in the pathogenesis and treatment of many causes of chronic liver disease. Objective - This study aimed to evaluate the association between serum vitamin D levels and the histopathological findings in patients with chronic hepatitis C virus infection. Methods - Cross-sectional study composed of patients with chronic hepatitis C. All patients underwent vitamin D 25 dosage and anthropometric data analysis. Liver biopsy was performed in a maximum 36-month period before inclusion in the study. Results - Of the 74 patients included in the study, 45 (60.8\%) were women, mean age was $57.03 \pm 9.24$ years, and $63(85.1 \%)$ were white. No association was observed between the serum levels of vitamin D and inflammatory activity $(P=0.699)$ nor with the degree of liver fibrosis $(P=0.269)$. Conclusion - In this study, no association was observed between vitamin $\mathrm{D}$ and inflammatory activity, as well as the degree of liver fibrosis, in patients with chronic hepatitis $\mathrm{C}$.

HEADINGS - Vitamin D. Chronic hepatitis C. Liver cirrhosis. Liver Diseases.

\section{INTRODUCTION}

Vitamin D has immunomodulatory, anti-inflammatory and antifibrotic properties, which are relevant in the treatment of many causes of chronic liver disease ${ }^{(12)}$.

Vitamin D deficiency has been observed in most patients with chronic liver disease ${ }^{(1,7)}$, regardless of the liver disease etiology ${ }^{(16,22)}$. An inversely proportional relationship has been described between vitamin D serum levels and liver fibrosis and response to antiviral treatment with interferon and ribavirin, as well ${ }^{(20)}$.

This study aimed to evaluate the association between vitamin D serum levels and inflammatory activity and degree of liver fibrosis in patients with chronic hepatitis $\mathrm{C}$ virus (HCV) infection.

\section{METHODS}

A cross-sectional study was developed in a convenience sample composed of patients with chronic HCV infection, with or without cirrhosis, between July 2012 and May 2013.

Seventy-four patients were consecutively included, considering the following: age 18 and over, chronic HCV infection, defined by positive anti-HCV serological test and confirmation of viremia by RNA-HCV. All patients underwent liver biopsy in a maximum 36-month period prior to the inclusion in the study. Patients must not have been under HCV treatment.

Patients with current or previous alcohol abuse problems
$(80 \mathrm{~g} / \mathrm{day})^{(19)}$ and coinfected by the hepatitis B (HBV) and/or human immunodeficiency viruses (HIV) were excluded from the study.

No patients were under vitamin D supplementation in the present or in the past. Vitamin D 25 serum concentration was evaluated in all patients by electrochemiluminescence method, using Roche Diagnostics Elecsys analyzer (Switzerland). To evaluate the vitamin D levels, the cutoff was established according to the Endocrine Society Clinical Practice Guideline: deficiency $\leq 20 \mathrm{ng} / \mathrm{mL}$; insufficiency $21-29 \mathrm{ng} / \mathrm{mL}$ and sufficiency $\geq 30 \mathrm{ng} / \mathrm{mL}^{(11)}$.

Age was analyzed using percentiles (p25/p50/p 75). The following anthropometric data were evaluated: weight, height and body mass index (BMI), calculated by the formula weight/height ${ }^{2(25)}$. Patients were not under nutritional monitoring.

Anti-HCV antibodies were detected by ELISA III test, in accordance with manufacturing instructions (Abbott Axsym System, N. Chicago/IL, EUA), followed by real-time polymerase chain reaction $(\mathrm{PCR})$.

Liver biopsy was performed as part of the clinical evaluation protocol to assess HCV treatment indication, using Metavir score ${ }^{(3)}$ for staging. The presence of cirrhosis was evaluated by clinical laboratory methods, image and histopathological analysis, whenever necessary.

This research was submitted and approved by the local Ethics Committee (number 3676/11) and presents minimum risk to the patients. All patients signed the Informed Consent in order to take part in the study.

Declared conflict of interest of all authors: none

Disclosure of funding: no funding received

Programa de Pós-graduação em Hepatologia da Universidade Federal de Ciências da Saúde de Porto Alegre (UFCSPA), RS, Brasil; ${ }^{2}$ Departamento de Nutrição da UFCSPA, RS, Brasil; ${ }^{3}$ Departamento de Clínica Médica da UFCSPA, RS, Brasil.

Correspondence: Kalinca da Silva Oliveira. Rua Múcio Teixeira, 156, 204. Bairro Menino Deus - CEP: 90050-360 - Porto Alegre, RS, Brasil. E-mail: ka.nutricionista@gmail.com 
The software MsExcel 2000 was used to store data; SPSS 19.0 (Statistical Package for Social Science) was used to analyze further results.

The quantitative variables are presented as mean and standard deviation. The qualitative variables are presented as frequency and percentage. The association between the continuous and ordinal variables with the vitamin $\mathrm{D}$ serum levels was evaluated by Spearman's correlation coefficient $\left(r_{s}\right)$. ANOVA and Chi-Squared test were used to verify the association when vitamin $\mathrm{D}$ serum levels was categorized. The significance level assumed was $5 \%$.

\section{RESULTS}

Seventy-four patients with HCV were included in the study; $45(60.8 \%)$ were women; mean age was $57.0 \pm 9.2$ years and 63 $(85.1 \%)$ were white.

Significant fibrosis (F3-F4) was observed in 36 (48.7\%) patients; moderate/severe inflammatory activity was found in $38(51.4 \%)$ patients (Table 1)

Nine $(12.2 \%)$ patients presented deficiency of vitamin D levels (below $20 \mathrm{ng} / \mathrm{mL}$ ). When age was evaluated considering the cutoffs for vitamin D levels (sufficiency, insufficiency and deficiency), a mean age of 55.65 \pm 9.24 years in those with sufficiency, $59.76 \pm 8.57$ years in those with insufficiency and a mean age of $59.22 \pm 9.88$ years in those with deficiency $(P=0.217)$ was observed.

There was no statistically significant differences between the mean vitamin $\mathrm{D}$ serum levels and different inflammatory activity or hepatic fibrosis degrees ( $P=0.700$ and $P=0.468$, respectively). Moreover, no association between vitamin $D$ serum levels and inflammatory activity $\left(\mathrm{r}_{\mathrm{s}}=0.099 ; P=0.416\right)$, or the degree of liver fibrosis $\left(\mathrm{r}_{\mathrm{s}}=-0.015 ; P=0.901\right)$ was observed.

Regarding the cutoffs of vitamin D levels (sufficiency, insufficiency and deficiency) there was no association with the inflammatory activity or the hepatic fibrosis degrees (Table 1).

\section{DISCUSSION}

No association between the vitamin D serum levels and the different degrees of inflammatory activity or liver fibrosis was found in this study. Some studies examined the relationship between the vitamin $\mathrm{D}$ serum level and the progression of the disease in patients with chronic hepatitis $C^{(5,10,12)}$, but this is a controversial issue.

It has been suggested that $\mathrm{HCV}$ reduces the production of 7-dehydrocholesterol, the precursor of endogenous vitamin D. Most patients presented low vitamin D levels, suggesting that $\mathrm{HCV}$ depresses serum levels and changes the lipid metabolism ${ }^{(6)}$.

Vitamin D deficiency is closely related to the severity of some chronic liver disease $\mathrm{e}^{(1,2,7,17,23)}$. Vitamin D anti-inflammatory and modulating properties could impact on disease progression especially on HCV chronic liver disease ${ }^{(12)}$. Some authors observed that vitamin $\mathrm{D}$ might have an impact on other outcomes and in the response to the treatment of patients with chronic hepatitis $C^{(8,18,21,26)}$.

In the present study, $9(12.2 \%)$ patients presented was observed deficiency. Similar results have been shown in the literature ${ }^{(9)}$ in the population with $\mathrm{HCV}$, although some reports present a high index of vitamin $\mathrm{D}$ deficiency/insufficiency.

A recent study ${ }^{(9)}$ showed an inverse relationship between vitamin D levels and viral load, liver fibrosis and treatment outcomes, supporting the hypothesis that the improvement of vitamin D status may have considerable potential to amend the host defense against $\mathrm{HCV}$ infection and response to therapy.

An independent association between low vitamin D serum level and higher degree of inflammatory activity has been suggested ${ }^{(4,13)}$. A probable explanation for the association between lower vitamin $\mathrm{D}$ levels and lower inflammatory activity in the liver would be the decrease of 25-hydroxylase activity, promoting decrease in vitamin D hydroxylation activity and, hence, lower serum levels ${ }^{(13)}$. However, this association was not observed in this study, corroborating Petta et al.'s findings ${ }^{(20)}$, putting in question this potential mechanism.

Some studies show that vitamin D serum levels are inversely related to liver fibrosis, showing a relationship between the anti-inflammatory effects ${ }^{(10,14,20)}$. Thus, vitamin D deficiency could contribute to a

TABLE 1. Mean vitamin D serum levels versus liver biopsy according the Metavir score $(\mathrm{N}=74)$

\begin{tabular}{lcccc}
\hline Variables & $\mathbf{N}(\%)$ & Sufficiency & Insufficiency & Deficiency \\
\hline Inflammatory activity** & & & & \\
Absent & $12(16.2)$ & $7(14.6 \%)$ & $4(23.5 \%)$ & $1(11.1 \%)$ \\
Minimum & $24(32.4)$ & $14(29.2 \%)$ & $6(35.3 \%)$ & $4(44.4 \%)$ \\
Mild & $33(44.6)$ & $24(50.0 \%)$ & $5(29.4 \%)$ & $4(44.4 \%)$ \\
Severe & $5(6.8)$ & $3(6.3 \%)$ & $2(11.8 \%)$ & $0(0.0 \%)$ \\
& & & & $1(11.1 \%)$ \\
Degree of fibrosis** & & & & 0.269 \\
Absence of fibrosis & $5(6.8)$ & $3(6.3 \%)$ & $5(0.0 \%)$ \\
Portal without septa & $12(16.2)$ & $7(14.6 \%)$ & $5(29.4 \%)$ & $1(11.1 \%)$ \\
Portal with rare septa & $21(28.4)$ & $17(35.4 \%)$ & $3(17.6 \%)$ & $4(44.4 \%)$ \\
Portal with numerous septa & $15(20.3)$ & $9(18.8 \%)$ & $2(11.8 \%)$ & $3(33.3 \%)$ \\
Cirrhosis & $21(28.4)$ & $12(25.0 \%)$ & $6(35.3 \%)$ & \\
\hline
\end{tabular}

* ng/mL: nanograms per milliliter. ** Metavir score. 
more advanced liver fibrosis and the use of supplementation should have an antifibrotic effect on HCV carriers ${ }^{(5)}$. On the other hand, Kitson et al. ${ }^{(13)}$ and Bitetto et al. ${ }^{(4)}$ did not find association between vitamin D serum levels and the degree of liver fibrosis in their studies, in which the contribuiting factors were not clear, with chances of being racial, genetic or methodological differences used in vitamin $\mathrm{D}$ analysis.

It should be questioned if vitamin $\mathrm{D}$ deficiency increases with age and the patients included in the present study should be quite young to assess this relationship. Vitamin D concentration was evaluated in individuals in the city of São Paulo belonging to different age groups ${ }^{(15)}$. A total of 591 individuals were included. The authors hypothesized that there would be cyclic patterns for the vitamin $\mathrm{D}$ and the UV radiation values that repeat every 12 months. They concluded that there was seasonal variation in the vitamin D concentration for all the groups studied; however, the amplitude of the variation was higher for the groups of young and physically active people, possibly due to the higher level of sunlight exposure for these groups. The lowest vitamin D concentration was detected in the spring. In the present study, however, this variable was analyzed and there was no association between age and vita- min D level when we considered the cutoffs for sunny countries established by Holick et al. ${ }^{(11)}$.

The fact that this study does not present data on the potential confounders that may influence vitamin D serum levels (sunlight exposure, use of medications or osteoporosis prevalence) can be considered as a limiting factor, although all patients collected the blood in the same season of the year.

Some authors reported that some drugs used for diabetes, for reducing cholesterol or diuretics may interfere lowering serum levels of vitamin $\mathrm{D}^{(24)}$. This may be an interesting observation, however, this was not evaluated in the present study.

In conclusion, there was no association between vitamin D serum levels and inflammatory activity or the degree of liver fibrosis in the patients with chronic HCV infection.

\section{Authors' contributions}

Tovo CV conceptualized the manuscript; Oliveira KS collected and analysed the data; Oliveira KS, Buss C and Tovo CV, wrote the paper; Buss C and Tovo CV performed the final review of the manuscript; all authors approved the final version of the manuscript.

Oliveira KS, Buss C, Tovo CV. Existe associação entre vitamina D e fibrose hepática em pacientes com hepatite C crônica? Arq Gastroenterol. 2017,54(1):57-9.

RESUMO - Contexto - A vitamina D é conhecida por possuir propriedades imunomoduladoras, anti-inflamatórias e antifibróticas, relevantes na patogênese e tratamento de muitas causas de doença hepática crônica. Objetivo - Este estudo tem como objetivo avaliar a associação entre os níveis séricos de vitamina D e os achados histopatológicos em pacientes com infecção crônica do vírus da hepatite C. Métodos - Estudo transversal, composto por pacientes com hepatite $\mathrm{C}$ crônica. Todos os pacientes foram submetidos à dosagem de vitamina $\mathrm{D} 25$ e análise de dados antropométricos. A biópsia hepática foi realizada em um período máximo de 36 meses antes da inclusão no estudo. Resultados - Dos 74 pacientes incluídos no estudo, 45 (60,8\%) eram mulheres, média de idade de 57,03 $\pm 9,24$ anos e 63 (85,1\%) eram brancos. Não foi observada associação entre os níveis séricos de vitamina D e atividade inflamatória $(P=0,699)$, nem com o grau de fibrose hepática $(P=0,269)$. Conclusão - No presente estudo, não foi observada associação entre a vitamina $\mathrm{D}$ e a atividade inflamatória, bem como com o grau de fibrose hepática, em pacientes com hepatite $\mathrm{C}$ crônica.

DESCRITORES - Vitamina D. Hepatite C crônica. Fibrose hepática. Hepatopatias.

\section{REFERENCES}

1. Arteh J, Narra S, Nair S. Prevalence of vitamin D deficiency in chronic liver disease. Dig Dis Sci. 2010;55:2624-8.

2. Baur K, Mertens JC, Schmitt J, et al. Combined effect of 25-OH vitamin D plasma levels and genetic vitamin D receptor (NR 1I1) variants on fibrosis progression rate in HCV patients. Liver Int. 2012; 32:635-43.

3. Bedossa P, Poynard T. An algorithm for the grading of activity in chronic hepatitis C. The METAVIR Cooperative Study Group. Hepatology. 1996;24:289-93.

4. Bitetto D, Fabris C, Fornasiere E, et al. Vitamin D supplementation improves response to antiviral treatment for recurrent hepatitis C. Transpl Int. 2011;24:43-50.

5. Cholongitas E, Theocharidou E, Goulis J, Tsochatzis E, Akriviadis E, Burroughs AK. Review article: the extra-skeletal effects of vitamin D in chronic hepatitis C infection. Aliment Pharmacol Ther. 2012;35:634-46.

6. Clark PJ, Thompson AJ, Vock DM, et al. Hepatitis C virus selectively perturbs the distal cholesterol synthesis pathway in a genotype-specific manner. Hepatology. 2012;56:49-56.

7. Fisher L, Fisher A. Vitamin D and parathyroid hormone in outpatients with noncholestatic chronic liver disease. Clin Gastroenterol Hepatol. 2007;5:513-20.

8. Gal-Tanamy M, Bachmetov L, Ravid A, et al. Vitamin D: an innate antiviral agent suppressing hepatitis $C$ virus in human hepatocytes. Hepatology. 2011;54:1570-9

9. Gerova DI, Galunska BT, Ivanova II, et al. Prevalence of vitamin D deficiency and insufficiency in Bulgarian patients with chronic Hepatitis $\mathrm{C}$ viral infection. Scand J Clin Lab Invest. 2014;9:1-8.

10. Gutierrez JA, Parikh N, Branch AD. Classical and emerging roles of vitamin D in hepatitis $C$ virus infection. Semin Liver Dis. 2011;31:387-98.

11. Holick MF, Binkley NC, Bischoff-Ferrari HA, et al. Evaluation, Treatment, and Prevention of Vitamin D Deficiency: an Endocrine Society Clinical Practice Guideline. J Clin Endocrinol Metab. 2011;96:1911-30.

12. Kitson MT, Roberts SK. D-livering the message: the importance of vitamin D status in chronic liver disease. J Hepatol. 2012;57:897-909.

13. Kitson MT, Dore GJ, George J, et al. Vitamin D status does not predict sustained virologic response or fibrosis stage in chronic hepatitis $\mathrm{C}$ genotype 1 infection. J Hepatol. 2013;58:467-72.
14. Lange CM, Bojunga J, Ramos-Lopez E, et al. Vitamin D deficiency and a CYP27B1-1260 promoter polymorphism are associated with chronic hepatitis C and poor response to interferon-alfa based therapy. J Hepatol. 2011; 54:887-93.

15. Maeda SS, Saraiva GL, Hayashi LF, et al. Seasonal variation in the serum 25-hydroxyvitamin D levels of young and elderly active and inactive adults in São Paulo, Brazil. The São Paulo Vitamin D Evaluation Study (SPADES). Dermatoendocrinol. 2013;5:211-7.

16. Malham M, Jørgensen SP, Ott P, et al. Vitamin D deficiency in cirrhosis relates to liver dysfunction rather than aetiology. World J Gastroenterol. 2011;17:922-5.

17. Masuda S, Okano T, Osawa K, Shinjo M, Suematsu T, Kobayashi T. Concentrations of vitamin D-binding protein and vitamin $\mathrm{D}$ metabolites in plasma of patients with liver cirrhosis. J Nutr Sci Vitaminol (Tokyo). 1989;35:225-34.

18. Matsumura T, Kato T, Sugiyama N, et al. 25-Hydroxyvitamin D3 suppresses hepatitis C virus production. Hepatology. 2012;56:1231-9.

19. Myncis M. Hepatite alcoólica. In: Mattos AA \& Dantas-Correa EB. Tratado de Hepatologia. Ed Rubio, 2010; 357-369 (Cohen RV, Roll S, Schaffa TD. Hernioplastia incisional videolaparoscópica. Rio de Janeiro: Reichmann \& Affonso, 1999;127-31.

20. Petta $\mathrm{S}$, Cammà C, Scazzone $\mathrm{C}$, et al. Low vitamin $\mathrm{D}$ serum level is related to severe fibrosis and low responsiveness to interferon-based therapy in genotype 1 chronic hepatitis C. Hepatology. 2010;51:1158-67.

21. Rahman AH, Branch AD. Vitamin D for your patients with chronic hepatitis C? J Hepatol 2013;58:184-9.

22. Rode A, Fourlanos S, Nicoll A. Oral vitamin D replacement is effective in chronic liver disease. Gastroenterol Clin Biol. 2010;34:618-20.

23. Schiødt FV. Gc-globulin in liver disease. Dan Med Bull. 2008;55:131-46.

24. Verdoia M, Schaffer A, Sartori C, et al. Vitamin D deficiency is independently associated with the extent of coronary artery disease. Eur J Clin Invest. 2014;44:634-42.

25. WHO expert consultation. Appropriate body-mass index for Asian populations and its implications for policy and intervention strategies. The Lancet. 2004;363:157-63.

26. Yano M, Ikeda M, Abe $\mathrm{K}$, et al. Comprehensive analysis of the effects of ordinary nutrients on hepatitis $\mathrm{C}$ virus RNA replication in cell culture. Antimicrob Agents Chemother. 2007;51:2016-27. 